\title{
Congenital Malaria in the Borgou/Alibori Regional University Teaching Hospital: Myth or Reality?
}

\author{
Joseph Agossou 1,2*, Falilatou Agbeille Mohamed1,2, Mèdétinmè Gérard Kpanidja ${ }^{1,2}$, \\ Alphonse Noudamadjo ${ }^{1,2}$, Julien Didier Adédémy ${ }^{1,2}$, Zinsou Rodrigue Ahodègnon ${ }^{1,2}$

\footnotetext{
${ }^{1}$ Department of Mother \& Child, Faculty of Medicine, University of Parakou, Parakou, Benin

${ }^{2}$ Pediatric Unit of the Borgou/Alibori Regional University Teaching Hospital, Parakou, Benin
} \\ Email: *agossoujoseph@gmail.com
}

How to cite this paper: Agossou, J., Mohamed, F.A., Kpanidja, M.G., Noudamadjo, A., Adédémy, J.D. and Ahodègnon, Z.R. (2019) Congenital Malaria in the Borgou/Alibori Regional University Teaching Hospital: Myth or Reality? Open Journal of Pediatrics, 9, 183-191.

https://doi.org/10.4236/ojped.2019.93018

Received: May 5, 2019

Accepted: July 6, 2019

Published: July 9, 2019

Copyright ( $\odot 2019$ by author(s) and Scientific Research Publishing Inc. This work is licensed under the Creative Commons Attribution International License (CC BY 4.0).

http://creativecommons.org/licenses/by/4.0/

\begin{abstract}
Introduction: The occurrence of malaria is classically described as uncommon or exceptional in the neonatal period. This work aims to describe the epidemiological, diagnostic, therapeutic, clinical features and outcomes of congenital malaria in the Borgou/Alibori Regional University Teaching Hospital (CHUD B/A) located in Parakou. Patients and Methods: This research is a cross-sectional and descriptive study that was conducted in the neonatal intensive care unit of the CHUD B/A from January to December 2017. It included and involved all newborns less than eight (08) days old with positive thick smears. Comorbidities were taken into account to establish the diagnosis of congenital malaria with accuracy. Findings: A total of 170 newborns out of 892 newborns admitted tested positive with Plasmodium falciparum thick smears, i.e., a hospital-based frequency of $19 \%$. The sex ratio was 1.1. The mean age was $22.44 \pm 2.72$ hours. There was malaria-bacterial infection comorbidity in $39.3 \%$ of cases. Among the 91 cases of thick smears testing positive without stigma of bacterial infection, G6PD deficiency and fetal-maternal Rhesus incompatibility, the main reasons for admission were prematurity (51.6\%), low birth weight (44\%), neonatal distress $(31.8 \%)$ and respiratory distress $(15.3 \%)$. In addition, the main signs found during the physical examination were neurological disorders or impairments (43.9\%), respiratory distress (30\%), hyperthermia $(12.1 \%)$ and jaundice $(4.4 \%)$. The mean or median parasitemia was 490 parasites $/ \mu$ l, with extremes ranging from 100 to 6500 parasites/ $\mu$ l. Treatment was based on artemisinin derivatives. The patient condition improved in $88.7 \%$ of cases. Overall mortality was estimated at $11.9 \%$, and the specific mortality was $13.2 \%$. Conclusion: Congenital malaria is a reality that actually prevails in the $\mathrm{CHUDB} / \mathrm{A}$. It has
\end{abstract}


become vital and urgent to explore innovative, effective and efficient strategies to ensure its management and prevention. A study using PCR as the gold standard should be conducted to better assess the extent and magnitude of the disease.

\section{Keywords}

Congenital Malaria, Prevention, Benin

\section{Introduction}

Malaria is a major public health issue. It mainly affects the tropical region of Africa, which is the focus of $80 \%$ to $90 \%$ of cases [1]. Pregnant women and children under five years of age represent the main risk groups. The occurrence of malaria during pregnancy is a leading underlying cause of fetal stillbirths and newborn mortality in endemic areas [2] [3]. In Sub-Saharan Africa, 25 million pregnant women are exposed every year to the risk for Plasmodium falciparum infestation, and one out of four pregnant women presents with signs of placental infestation during childbirth [4]. Gestational malaria has multiple consequences. Those with a direct impact on the fetus and newborn are stillbirths, prematurity, intrauterine growth restrictions (IUGR) and congenital malaria [4] [5].

Actually, congenital malaria is defined as the clear presence of asexual forms of Plasmodium parasites in the newborn's peripheral blood before the seventh day of life [6] [7]. This disease has often been depicted as uncommon, rare and even exceptional, but prevalences vary between 0 and $46 \%$ in Sub-Saharan Africa [8].

The clinical signs observed in the newborn are nonspecific and similar to those of other diseases, mainly bacterial infections [9].

In Benin, a study has confirmed the existence of congenital malaria with a frequency of $19 \%$ [10]. However, its clinical expression, management and prognosis have not been broadly discussed. Moreover, there is no consensus on the treatment of newborns with congenital malaria.

Therefore, this research aims to describe the epidemiological, diagnostic, therapeutic features and outcomes of congenital malaria at the Borgou/Alibori University Teaching Hospital (CHUD-Borgou/Alibori).

\section{Patients and Methods}

This work is a cross-sectional and descriptive study with prospective data collection carried out in the neonatal care unit of the Borgou/Alibori University Teaching Hospital (CHUD B/A) from January 1 to December 31, 2017. This study has been approved by the administrative authorities of the hospital and the head of the pediatric department. The informed consent of the parents was obtained and the anonymity of the patients included was respected. 
The study population consisted of newborns admitted to the said unit during the study time span. A thick smear/parasite count was systematically performed on any newborn admitted to the neonatology unit. The study included all newborns at less than eight (08) days of life, in whom a thick smear/parasite count tested positive in peripheral blood. On admission, an obstetric anamnesis was performed. It included an accurate collection of data related to the course of pregnancy, malaria prophylaxis (use of long-lasting insecticide-treated nets/LLINs, use of sulfadoxine-pyrimethamine/SP for intermittent preventive treatment during pregnancy/IPTp), child delivery conditions and postnatal care. These data were collected followed by a physical examination with recording of vital signs and examination of the different apparatuses. A thick smear/parasite count was systematically performed in all the newborns included from the collection of peripheral blood. To diagnose congenital malaria with accuracy and eliminate comorbidities, additional tests were performed according to etiologic guidance. The additional tests included complete blood count, measurement of C-reactive protein (CRP), cytobacteriological and biochemical examination of the cerebrospinal fluid, rhesus blood typing, and measurement of G6PD. Newborns with thick smears testing positive without stigma of bacterial infection, G6PD deficiency and risk for fetal-maternal incompatibility were considered to have isolated congenital malaria. Newborns presenting with positive and asymptomatic thick smear/parasite counts were treated using an artemisinin-based combination therapy (ACT); those who were symptomatic were placed on intravenous artesunate at a dose of $3 \mathrm{mg} / \mathrm{kg} /$ day at H0, H12 and H24, alternated with ACT. Entry and processing of the data were carried out using the EPI info 3.5.3 software.

\section{Findings}

\section{1) Hospital-based frequency of congenital malaria}

Among the 892 newborns admitted to the neonatal care unit during the study period, 170 were infected with malaria, i.e., a hospital-based frequency of $19 \%$.

2) Sociodemographic characteristics of mothers and gestational anamnesis data

The mothers' mean age was $27.3 \pm 6$ years with extremes ranging from 15 to 42 years. They were housewives in $30 \%$ of cases, and $62.9 \%$ were multiparous. Table 1 summarizes the obstetric anamnesis data concerning newborns infected with malaria.

\section{3) Characteristics of newborns infected with malaria}

Concerning all 170 newborns infested by Plasmodium, the sex ratio was 1.1. Newborns had a mean gestational age of 36.9 weeks of amenorrhea (WA), with extremes from 30 to $42 \mathrm{WA}$. The mean age of the newborns on admission was $22.44 \pm 2.72$ hours; the mean weight was $2616.5 \pm 711.2 \mathrm{~g}$, with extremes ranging from 890 to $4000 \mathrm{~g}$, of which $41.1 \%$ had weighed than $2500 \mathrm{~g}$.

4) Diagnostic features of congenital malaria in included newborns

The reasons for admission among the 170 newborns infested by Plasmodium, 
Table 1. Data on obstetric anamnesis of newborns infected with malaria.

\begin{tabular}{|c|c|c|}
\hline & Population size $(n=170)$ & $\%$ \\
\hline \multicolumn{3}{|c|}{ Number of antenatal care (ANC) } \\
\hline$<4$ & 78 & 45.8 \\
\hline$\geq 4$ & 92 & 54.2 \\
\hline \multicolumn{3}{|c|}{ Use of long-lasting insecticide-treated nets (LLINs) } \\
\hline Yes & 146 & 86 \\
\hline No & 24 & 14 \\
\hline \multicolumn{3}{|l|}{ IPT } \\
\hline Yes & 75 & 44.1 \\
\hline No & 95 & 55.9 \\
\hline \multicolumn{3}{|c|}{ Gestational age } \\
\hline$<37$ & 90 & 53 \\
\hline$>37$ & 70 & 47 \\
\hline \multicolumn{3}{|c|}{ Fever during childbirth } \\
\hline Yes & 16 & 9.5 \\
\hline No & 154 & 90.5 \\
\hline \multicolumn{3}{|c|}{ Premature rupture of membranes } \\
\hline Yes & 30 & 17.7 \\
\hline No & 140 & 82.3 \\
\hline
\end{tabular}

were mainly neonatal distress (29.1\%), prematurity (16.4\%) and fever (12.4\%). Of the 170 newborns infested by Plasmodium, 91 had isolated congenital malaria, and 79 had other comorbidities. The main comorbidity was bacterial infection (39.3\%). Among the newborns presenting with isolated congenital malaria, 38 (41.8\%) were asymptomatic, and 53 (58.2\%) were symptomatic. The physical signs identified in those symptomatic newborns were neurological signs (hypotonia, convulsions, disturbed primitive reflexes) in $43.9 \%$ of cases, respiratory distresses in $30 \%$ of cases, fever in $12.1 \%$ of cases and jaundice in $4.4 \%$ of cases. Perinatal asphyxia without other obvious causes was found in 13 newborns, i.e., $14.3 \%$.

Table 2 shows the main clinical signs found in newborns presenting with isolated congenital malaria.

Concerning biological aspects, Plasmodium falciparum was the only plasmodium species identified with a mean parasite count of 490 parasites/ $\mu$ l and extremes ranging from 100 to 6500 parasites $/ \mu$.

5) Therapeutic features and outcome

All the asymptomatic newborns received artemisinin-based therapy combinations: artesunate-piperaquine; symptomatic newborns were administered artesunate by the intravenous route during the first 24 hours alternated with artesunate-piperaquine for 72 hours. The other comorbidities were also managed in 
Table 2. Distribution of newborns presenting with isolated congenital malaria according to clinical signs $(\mathrm{N}=91)$.

\begin{tabular}{|c|c|c|}
\hline & Population size & $\%$ \\
\hline \multicolumn{3}{|l|}{ Reasons for admission } \\
\hline Prematurity & 47 & 51.6 \\
\hline Low birth weight & 40 & 44 \\
\hline Severe fetal distress & 29 & 31.8 \\
\hline Respiratory distress & 14 & 15.3 \\
\hline Hypotonia & 14 & 15.4 \\
\hline Fever & 11 & 12.1 \\
\hline Refusal to suck the mother's breast & 10 & 11 \\
\hline Jaundice & 4 & 4.4 \\
\hline Convulsions & 3 & 3.3 \\
\hline \multicolumn{3}{|l|}{ Physical signs on admission } \\
\hline Respiratory distress & 27 & 30.0 \\
\hline Disturbed primitive reflexes & 21 & 23.1 \\
\hline Fever & 11 & 12.1 \\
\hline Pallor & 5 & 5.5 \\
\hline Convulsion & 5 & 5.6 \\
\hline Jaundice & 4 & 4.4 \\
\hline Anemia & 2 & 2.2 \\
\hline
\end{tabular}

compliance with the protocol applicable in the medical unit. The transfusion of packed red blood cells (PRBCs) was performed in 11 cases (6.4\%). The patient health status improved in $88.7 \%$ of cases. Twenty out of the 170 newborns died, i.e., an overall mortality rate of $11.9 \%$. Among the newborns who presented with isolated congenital malaria, 12 deaths were registered, i.e., a specific mortality of $13.2 \%$. Among those 12 newborns who died, $7(7.7 \%)$ were premature and had a low birth weight $(<2500 \mathrm{~g}), 3(3.3 \%)$ were mature eutrophic, $2(2.2 \%)$ were full-term hypotrophic, and 11 (12.1\%) were symptomatic.

\section{Discussion}

The purpose of this work was to describe the epidemiological, clinical and therapeutic features and outcomes of newborns presenting with congenital malaria.

\section{1) Epidemiological features}

Regarding epidemiological aspects, the $19 \%$ frequency reported in this research is identical to that found by Noudamadjo et al. [10] in the same hospital unit in 2012. This frequency is in the range described in the literature in Sub-Saharan Africa [8] and is close to the one found by Runsewe-Abiodun et al. in Nigeria in 2006 [11], i.e., 17.4\%, and by Chiabi et al. in Cameroon in 2012 [12], i.e., 23.7\%. Other authors, such as Asse et al. in Bouaké (Côte d'Ivoire) and Fea 
Lesi et al. and Olabisi et al. in Nigeria [13] [14] [15], have reported lower frequencies of $10.5 \%, 13.6 \%$ and $2 \%$, respectively. This variability of the frequencies observed may be due to the diversity of methodologies used by the different studies, type of blood sample examined (peripheral blood or umbilical cord blood), methods of biological diagnosis used, expertise in thin smear examination, and method of parasite detection. The said variability may also and mainly be due to the distinct epidemiological features of the different countries [5]. The high frequency noted in our study may also be associated with the low coverage of intermittent preventive treatment (IPT) of pregnant women. In view of our findings, we can say that in our context, congenital malaria is not an uncommon event. That is why any newborn admitted to a neonatal care unit in a country such as Benin (characterized by a stable epidemiological feature of malaria with long seasonal transmission) should benefit from systematic thick smears in order to detect Plasmodium.

\section{2) Clinical and biological features}

Concerning clinical aspects, congenital malaria is described as an uncommon disease. This uncommon nature would be associated with the following factors: transfer of anti-malaria antibodies from mother to fetus, presence of fetal hemoglobin in the newborn, young age and enzymatic environment of the newborn. These factors would be detrimental to the development of the parasite [16] [17]. Additionally, according to the literature data, in the case of vertical transmission, $70 \%$ of the plasmodia would be destroyed within two to three days after birth [18] [19]. This fact may explain why some newborns infected with malaria are asymptomatic.

In our study, $58.2 \%$ of newborns were symptomatic. Our result is similar to that reported by Okoli et al. in Nigeria [20] where the epidemiological facies of malaria is the same as ours.

In contrast, Nagalo et al. [21] in Burkina Faso and Balaka et al. in Togo [22] have reported frequencies of $24.4 \%$ and $1.7 \%$, respectively, which are lower than our reported frequencies. Often, the incidence of congenital malaria is underestimated. In the literature, two forms of disease have been described, but in reality, these two forms represent only one entity with, on the one hand, infra-clinical signs that must be called "congenital malaria infection" and, on the other hand, obvious clinical signs that should be called "congenital malaria disease". However, the clinical features associated with positive tests of thick smears do not enable the first distinction of those two forms of congenital malaria when a neonatal bacterial infection is associated with them [12] [22] [23].

The clinical signs of congenital malaria are nonspecific like those in neonatal bacterial infections. In our work, such symptoms mainly included neurological signs (43.9\%), respiratory distress (30\%), fever (12.1\%) and neonatal jaundice (4.4\%). Those clinical signs have been identified by several authors in different proportions [12] [13] [22]. Additionally, 14.3\% of the newborns presenting with isolated congenital malaria had perinatal asphyxia. Therefore, in our context, it 
would be no exaggeration to associate perinatal asphyxia, the cause of which is unexplained (nonobvious), with malarial infestation. Neurological signs were present in $100 \%$ of newborns in the study of Balaka et al. [22] and in $87.5 \%$ of newborns in the study of Asse et al. [13]. These signs are indicative of cerebral pain. The cerebral pain noted may occur just after fetal hypoxia. Fetal hypoxia would be the outcome of reduced exchanges through the fetus's umbilical cord blood. Actually, in the context of malaria, the placenta is characterized by an excess of large and diffuse whitish areas corresponding to perivillous fibrin depositions of compact and dark placentas as signs of reduced maternal blood flow [24].

Fever was identified in $12.1 \%$ of newborns. Nagalo et al. [21] found a predominance of fever in $48.3 \%$. According to published studies, fever is an unpredictable sign with variable frequencies [14] [15].

Neonatal jaundice was found in $4.4 \%$ of newborns. This sign has been commonly observed in what some authors have referred to as "congenital malaria disease". In addition, a significant association has been identified between the occurrence of jaundice on the seventh day of life and this type of congenital malaria [9] [14].

As far as biological aspects are concerned, Plasmodium falciparum was the only plasmodium species identified. This species is fearsome due to its recognized severity and has been detected by most authors in West Africa [8]-[13].

\section{3) Therapeutic features and outcome}

Among the asymptomatic newborns put on ACT, none showed clinical symptoms after three days of treatment.

Artemisinin derivatives were used in all newborns infected with malaria, and the health condition improved in $88.7 \%$ of them. Care protocols are different depending on the author; some authors [21] [22] used quinine perfusion to provide care to symptomatic newborns; other authors [12] used quinine alternated with ACT. Some of them [13] chose artemether in symptomatic newborns infected with malaria and therapeutic abstention in newborns who were asymptomatic. We believe that due to the severe potential of Plasmodium falciparum malaria, all newborns with malaria should be treated, whether symptomatic or not. This variability noted in the provision of care to newborns may be due to the lack of a regional or international consensus on the management of congenital malaria. Overall mortality was estimated at $11.9 \%$, and the specific mortality was $13.2 \%$. Although it cannot be attributed to malaria only, this high mortality requires particular attention. For instance, given that malaria in pregnancy is a cause of prematurity, low birth weight and fetal hypotrophy, in our investigation, we registered 9 deaths out of 12 among the cases of isolated congenital malaria that were either premature, with low birth weight or hypotrophic. In the literature, the mortality rate varies, depending on the study, from 0 to $25 \%$ [18] [21] [22]. As our study was carried out in a hospital with a biological diagnosis based on a thick smear/parasite count using newborns' peripheral blood, which 
is currently the gold standard, our findings could not reflect the actual situation of congenital malaria in Benin.

\section{Conclusions}

Congenital malaria is a reality that prevails in the CHUD Borgou/Alibori. The predominant clinical features are neurological and respiratory signs as well as fever and jaundice, which often suggested a neonatal bacterial infection.

Any newborn admitted to a neonatal care unit must be allowed to benefit from a thick smear/parasite count, regardless of the reason for his/her admission. Furthermore, a study using PCR as the gold standard should be conducted to better assess the extent and magnitude of the disease.

\section{Conflicts of Interest}

The authors declare no conflicts of interest regarding the publication of this paper.

\section{References}

[1] Bouchaud, O., Doumbo, O., Gaye, M., Ogutu, B., Soumare, M., et al. (2008) Memento Therapeutics of Malaria in Africa. Doin, Paris.

[2] Fischer, P.R. (1997) Congenital Malaria: An African Survey. Clinical Pediatrics, 36, 411-413. https://doi.org/10.1177/000992289703600706

[3] Breman, J.G., Alilio, M.S. and Mills, A. (2004) Conquering the Intolerable Burden of Malaria: What's New, What's Needed: A Summary. The American Journal of Tropical Medicine and Hygiene, 71, 1-15. https://doi.org/10.4269/ajtmh.2004.71.2_suppl.0700001

[4] Desai, M., Ter Kuile, F.O., Nosten, F., McGready, R., Asamoa, K., Brabin, B. and Newman, R.D. (2007) Epidemiology and Burden of Malaria in Pregnancy. The Lancet Infectious Diseases, 7, 93-104. https://doi.org/10.1016/S1473-3099(07)70021-X

[5] Menendez, C. and Mayor, A. (2007) Congenital Malaria: The Least Known Consequence of Malaria in Pregnancy. Seminars in Fetal \& Neonatal Medicine, 12, 207-213. https://doi.org/10.1016/j.siny.2007.01.018

[6] Larkin, G.L. and Thuma, P.E. (1991) Malaria Congenital in a Hyper-Endemic Area. The American Journal of Tropical Medicine and Hygiene, 45, 587-592. https://doi.org/10.4269/ajtmh.1991.45.587

[7] Ligny, C., de Gentile, L., Chabasse, D., et al. (1989) Malaria and Pregnancy. Report of an Observation of Plasmodium falciparum Congenital Malaria. Annals of Pediatrics (Paris), 36, 669-674.

[8] Uneke, C.J. (2007) Congenital Plasmodium falciparum Malaria in Sub-Saharan Africa: A Rarity or Frequent Occurrence. Journal of Parasitology Research, 101, 835-842. https://doi.org/10.1007/s00436-007-0577-9

[9] Ekenam, A.D., Anah, M.U. and Udo, J.J. (2008) The Prevalence of Congenital Malaria among Neonates with Suspected Sepsis in Calabar, Nigeria. Tropical Doctor, 38, 73-76. https://doi.org/10.1258/td.2007.005274

[10] Noudamadjo, A., Sagbo, G.G., Adédémy, J.D., Agossou, J., Obossou, A.A. and Lokossou, S.D. (2017) Frequency and Sociodemographic Factors Associated with 
Congenital Malaria in the Borgou Regional University Teaching Hospital (CHUD-B) in Benin in 2015. Open Journal of Pediatrics, 7, 215-221. https://doi.org/10.4236/ojped.2017.74025

[11] Runsewe-Abiodun, I.T., Ogunfowora, O.B. and Fetuga, B.M. (2006) Neonatal Malaria in Nigeria: A 2-Year Review. BMC Pediatrics, 6, 19.

https://doi.org/10.1186/1471-2431-6-19

[12] Chiabi, A., Lendem, I., Kobela, M., Mah, E., Tietche, F. and Tchokoteu, P. (2012) Incidence of Congenital Malaria in Two Neonatal Intensive Care Units of Yaoundé, Cameroon. Journal of Pediatrics and Child Care, 25, 301-308. https://doi.org/10.1016/j.jpp.2012.08.001

[13] Assé, K.V., Yao, K.C., Avi, C., Aka, K.A., Yenan, J.P., et al. (2017) Congenital Malaria in Bouaké (Côte d'Ivoire): Findings of a Prospective Study about 28 Cases. Journal Africain de Pédiatrie et de Génétique Médicale, 1, 22-27.

[14] Lesi, F.E.A., Mukhtar, M.Y., Iroha, E.U. and Egri-Okwadji, M.T.C. (2010) Clinical Presentation of Congenital Malaria at the Lagos University Teaching Hospital. $\mathrm{Ni}$ gerian Journal of Clinical Practice, 13, 134-138.

[15] Okechukwu, A.A., Olateju, E.K. and Olunde, E.O. (2011) Congenital Malaria among Newborns Admitted for Suspected Neonatal Sepsis in Abuja. Nigerian Journal of Pediatrics, 38, 82 -89. https://doi.org/10.4314/njp.v38i2.72250

[16] Fischer, P.R. (2003) Malaria and Newborns. Journal of Tropical Pediatrics, 49, 132-134. https://doi.org/10.1093/tropej/49.3.132

[17] Pasvol, G., Weatherall, D.J. and Wilson, R.J. (1977) Effects of Fœatal Haemoglobin on Susceptibility of Red Cells to Plasmodium falciparum. Nature, 270, 171-173. https://doi.org/10.1038/270171a0

[18] Falade, C., Mokuolu, O., Okafor, H., et al. (2007) Epidemiology of Congenital Malaria in Nigeria: A Multi-Centre Study. Tropical Medicine \& International Health, 12, 1279-1287. https://doi.org/10.1111/j.1365-3156.2007.01931.x

[19] Okafor, U.H., Oguonu, T. and Onah, H.E. (2006) Risk Factors Associated with Congenital Malaria in Enugu, South Eastern Nigeria. Journal of Obstetrics and Gynaecology, 26, 612-616. https://doi.org/10.1080/09638280600902893

[20] Okoli, C.A., Okolo, S.N. and Collins, J.C. (2013) Plasmodium falciparum Infection among Neonates in the North Central Region of Nigeria. The Journal of Infection in Developing Countries, 7, 365-371. https://doi.org/10.3855/jidc.2775

[21] Nagalo, K., Dao, F., Minodier, P., Sawadogo, O., Sanon, H., Tall, H.F. and Yé, D. (2014) Congenital Plasmodium falciparum Malaria: Epidemiological, Clinical, Biological, Therapeutic and Prognostic Aspects in Ouagadougou, Burkina Faso. Pan African Medical Journal, 18, 47. https://doi.org/10.11604/pamj.2014.18.47.3614

[22] Balaka, B., Agbere, A.D., Bonkoungou, P., Kessie, K., Assimadi, K. and Agbo, K. (2000) Congenital Plasmodium falciparum Malaria Disease in the Newborn with Infection Risk. Archives de Pédiatrie, 7, $243-248$. https://doi.org/10.1016/S0929-693X(00)88739-4

[23] Hulbert, T.V. (1992) Congenital Malaria in the United States: Report of a Case and Review. Clinical Infectious Diseases, 14, 922-926. https://doi.org/10.1093/clinids/14.4.922

[24] Philippe, E. and Walter, P. (1985) Placental Injuries of Malaria. Archives Francaises de Pediatrie, 42, 921-923. 